\title{
Impact analysis of geotechnical occurrences in ECP projects cost control
}

\author{
María-Belén Prendes-Gero (Main and Corresponding Author) \\ Universidad de Oviedo, EPSIG, Departamento de Construcción \\ Departmental Building 6, 33204, Gijón, Asturias (Spain) \\ mbprendes@uniovi.es
}

\section{Celestino González-Nicieza}

Universidad de Oviedo, EIMEM, Departamento de Explotación y Prospección de Minas

C/Independencia 13, 33004, Oviedo, Asturias (Spain)

cgonzalez@uniovi.es

\section{Víctor Ordiales-Martínez}

TSK. Departamento Civil

C/Ada Byron 220, 33203, Gijón, Asturias (Spain)

victor.ordiales@grupotsk.com

\section{Martina-Inmaculada Álvarez-Fernández}

Universidad de Oviedo, EIMEM, Departamento de Explotación y Prospección de Minas.

C/ Independencia 13, 33004, Oviedo, Asturias, España

inma@uniovi.es

Manuscript Code: 1157

Date of Acceptance/Reception: 02.08.2019/03.08.2018

DOI: $10.7764 /$ RDLC.18.3.418

\section{Abstract}

Engineering, procurement, and construction (EPC) contracts are the most widespread way to carry out the execution of complex projects. Under an EPC contract modality, the contractor must must complete the installation at a guaranteed price and by a specific date, while reaching the agreed level of quality and performance for the installation. Failure to comply with any of the above requirements usually results in the application of economic penalties. Therefore, the main problem of a fixed price EPC contract is that any unexpected problem will be reflected in the final economic result of the contract. There are three main problems that can endanger the final result: a) Unexpected failure that does not represent a time delay but involves the rehabilitation costs; b) Unexpected failure that endangers the facility delivery date and therefore involves a penalty fee; c) Erroneous selection of the involved regulations in the design of the project. Since the exposed problems are quite common, the aim of this paper is to give an approach, in economic terms, of the unexpected costs related to geotechnical issues. This analysis will be carried out using three real EPC construction projects. The selected examples will cover different perspectives: Case 1; the main cost is the execution of the rehabilitation. Case 2; the main cost is the penalty fee due to start up delay. Case 3; the cost depends on the applicable regulations.

Keywords: failure, regulations, cost control, rehabilitation, penalty fee.

The detailed contractual structure varies from project to project. However, most projects have a basic structure as illustrated below (Figure 1) (Mcnair, 2011). As can be seen in the diagram, the project company usually reach agreements that cover the following elements:

- An agreement that gives the project company the right to construct and operate the power station and sell electricity generated by the power station.

- In traditional project-financed power plants projects, there is a power purchase agreement (PPA) between the project company and the local government authority: the government authority undertakes to pay for a set amount of electricity for every year of the concession.

- A construction contract governing the construction of the power station.

- An agreement governing the operation and maintenance of the power station.

- $\quad$ An agreement governing the supply of fuel to the power station.

- $\quad$ Financing and security agreements with lenders to finance the development of the project. 
Figure 1. Basic contractual structure of an EPC project. Source:(Mcnair, 2011). EPC Contracts in the Power Sector.

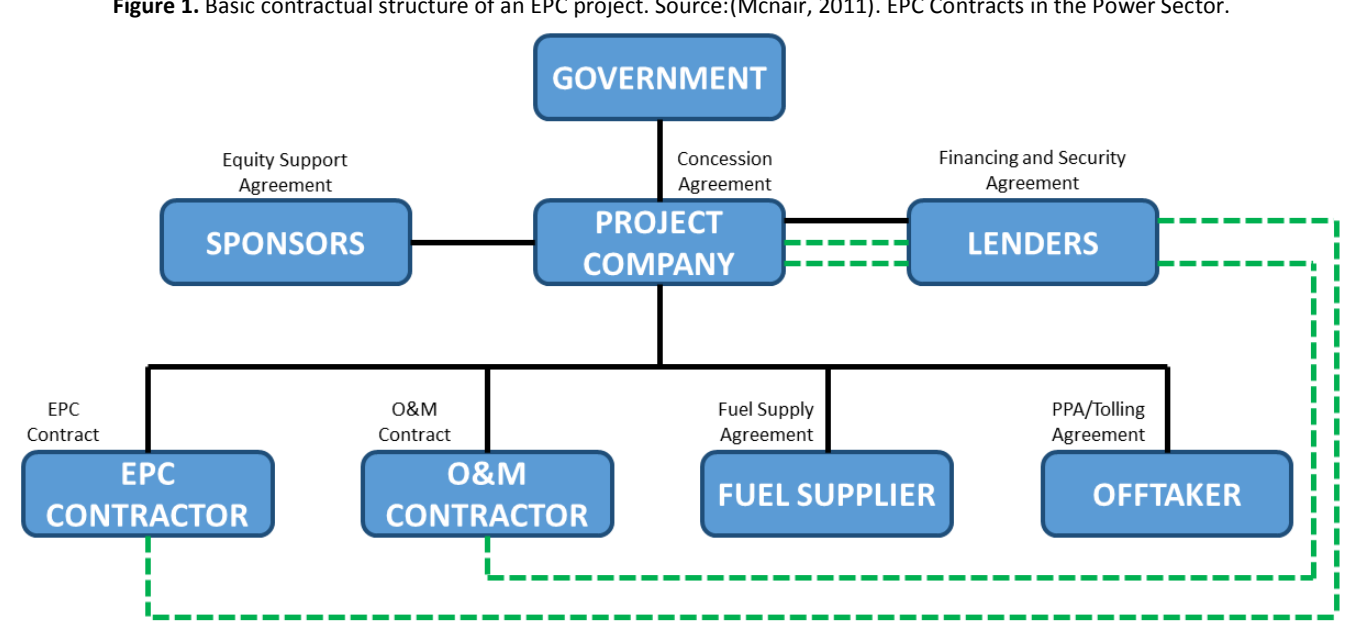

The key clauses in any construction contract are those that impact on: Time, Cost and Quality, but as EPC contracts tend to deal with issues with a greater sophistication than other types of construction contracts, they must provide for:

1. A single point of responsibility. The contractor is responsible for all design, engineering, procurement, construction, commissioning and testing activities.

2. A fixed contract price. The risk of cost overruns and the benefit of any cost savings are borne by the contractor.

3. A fixed completion date. EPC contracts include a guaranteed completion date, which is either a fixed date or a fixed period after the commencement of the EPC contract. If this date is not met, the contractor is liable for delayliquidated damages.

4. Performance guarantees. The project company's revenue is earned by operating the power station. Therefore, it is vital that the power station performs as required in terms of output, efficiency, and reliability.

Based on the previously exposed arguments, it is clear that the occurrence of unforeseen geotechnical issues during the construction phase will mean re-evaluating the final project's economic outcome. Since it is a fixed contract price, the engineering hours required to evaluate the problem and develop a solution, damaged material replacement, and new purchases are extra costs that will reduce the project's profitability. In addition, all those unexpected extra works have a time cost that will make it more difficult to finish the construction without any time penalties.

Description of the problem

As previously stated, three main problems can endanger the outcome of the contract:

a) Unexpected failure that does not represent a time delay but involves an increase in the costs due to the rehabilitation.

b) Unexpected failure that endangers the facility delivery date and therefore involves a penalty fee.

c) Erroneous selection of the involved standards in the design of the project.

The selected examples to develop the cost assessment cover all the perspectives:

a) Case 1 - The main cost is the execution of the rehabilitation.

b) Case 2 - The main cost is the penalty fee due to start up delay.

c) Case 3 - The cost depends on the selected standards.

\section{Case 1 problem description}

The solar thermal plant La Asturiana is located in the Southern Spain. It is a solar plant covering a surface area of $2 \mathrm{Mm}^{2}$ and a generation capacity of $50 \mathrm{MW}$.

The pluvial water collector object of this research is made of reinforced concrete ( $250 \mathrm{~mm}$ thick) and it extends in the solar plant from north to south ( $1500 \mathrm{~m}$ in length and with a maximum depth of $15 \mathrm{~m}$ ). The first section of about $620 \mathrm{~m}$ has a diameter of $1800 \mathrm{~mm}$, while the second section of about $880 \mathrm{~m}$ has a diameter of $2500 \mathrm{~mm}$. Along $400 \mathrm{~m}$ of the latter section; longitudinal cracks were detected on the walls of the concrete pipe shortly after its construction but before its commissioning.

This pipe has very unusual characteristics, not because of the $2500 \mathrm{~mm}$ diameter but because of a filling of up to $15 \mathrm{~m}$ in its most unfavourable section, being about $12 \mathrm{~m}$ for the majority of its path. Therefore, its design was based on the 
handbook "Concrete pipe design manual", edited by the American Concrete Pipe Association (Concrete Pipe Design Manual, 2011).

The pathologies found in the pipe appeared in the form of interior longitudinal cracks, both at the crown and the invert of the pipe (Figure 2).

Figure 2. Observed damage. Source: Own elaboration (2017).
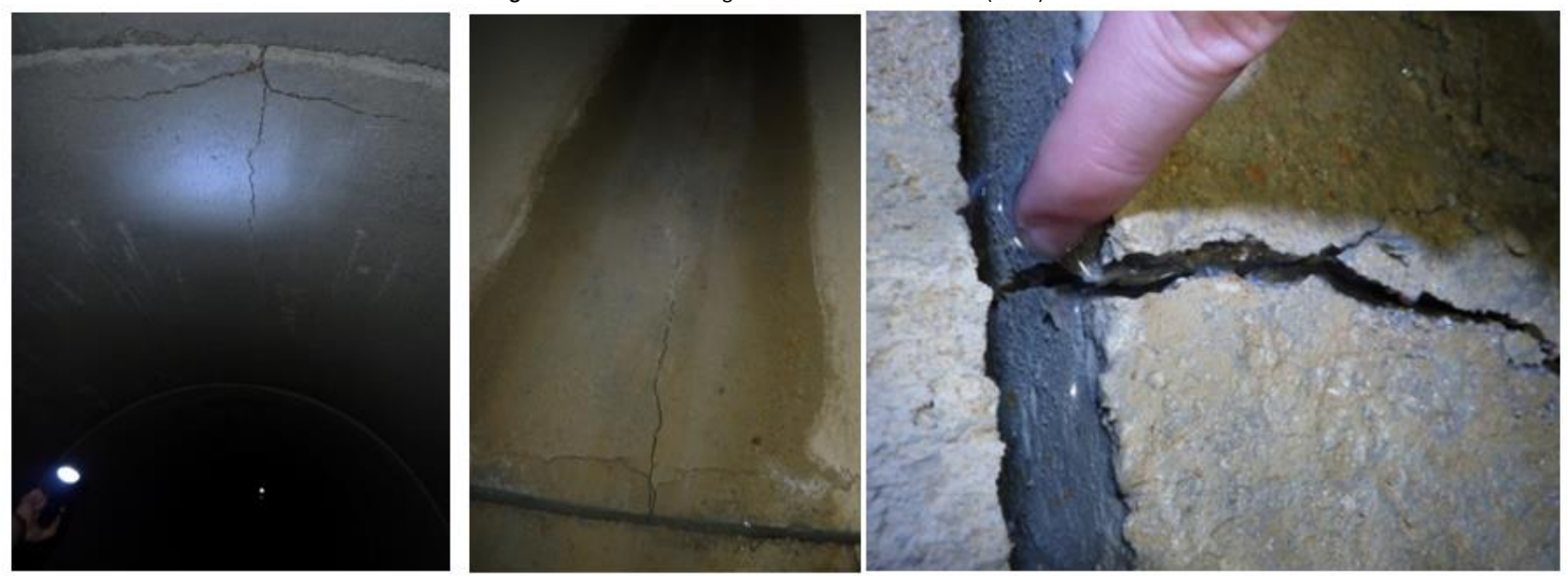

At this point, the construction works related to the rainwater network must stop, and therefore, a time delay starts running against the project schedule.

Furthermore, as explained in the abstract, at this moment the engineering department is involved again in order to understand the problem and develop a technical solution. At this point, the project costs start to increase.

\section{Case 2 problem description}

An essential section in the normal operation of a solar thermal plant is the management of those effluents, which are generated through several processes that take place in the power plant. Due to environmental regulations, it is necessary to develop an effluent treatment plant before all those fluids can be discharged into the environment. In such a plant, a neutralization process is developed, by adding certain chemicals, resulting in an environmentally safe spill.

Throughout the execution of this kind of facility in the solar thermal plant, all design requirements were fulfilled, and the execution phase was carried out without any incident.

Nevertheless, during the commissioning of the facility, some equipment showed settlements that were much higher than the established limits, which led to a temporary shutdown of the facility. Those settlements had an immediate effect in the supported structures, leading to excessive deflections and reaching dangerous inclinations, as can be seen in Figure 3.

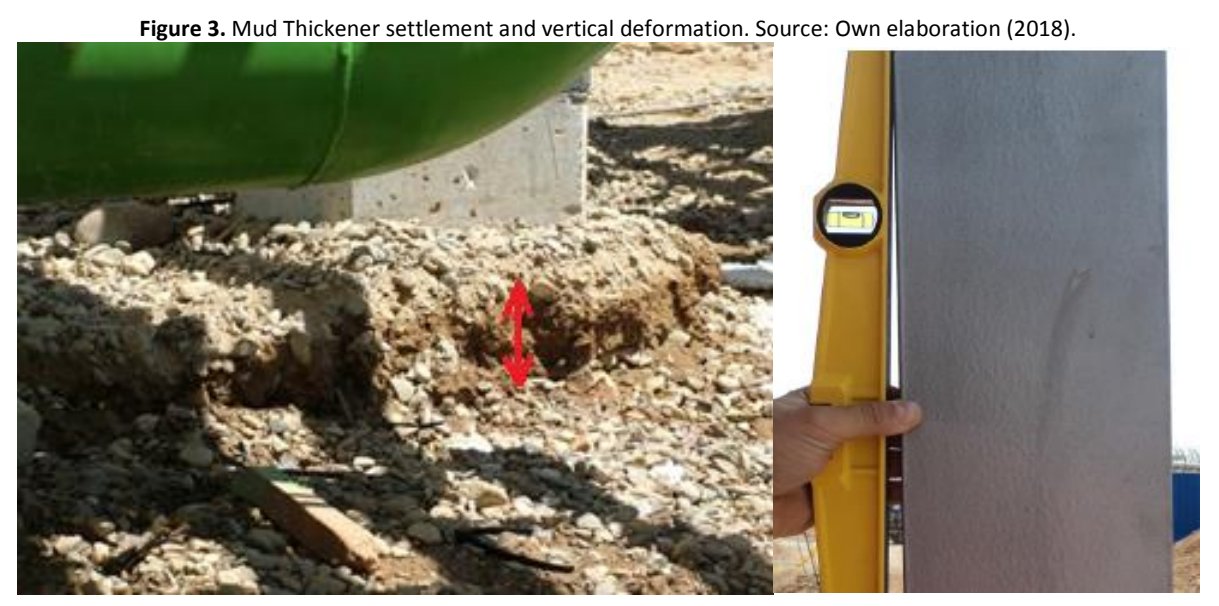


The subsidence phenomena have been previously documented in Southern Spain (Herrera, Fernández, Tomás, Cooksley, \& Mulas, 2009), so, in order to solve this unforeseen issue, the engineering team was involved again in the process.

At this point, the commissioning phase and therefore the finishing date, started to accumulate delays, endangering the start-up milestone and thus the appearance of the time penalty risk.

\section{Case 3 problem description}

During the engineering phase of industrial projects, one of the most important tasks is to analyse the applicable standards and regulations of the project. These can be found in the local regulations, in the bidding documentation or, even, in the contract. Nevertheless, there are usually certain design aspects that are not covered or included in the local regulations of most developing countries. Therefore, it is the designer's decision to select the most appropriate standard. One of the factors, which are usually in this regulation void, is the liquefaction phenomena.

This section tries to expose the impact, in terms of associated costs, which an appropriate selection of the involved regulations at the beginning of the project has and how the effective use of a higher number of engineering hours is widely rewarded with elevated savings during the construction phase.

In order to develop a consistent analysis, a real construction case will be explained. It consists of deep foundation design, in a soil with high liquefaction potential, along the construction of a natural gas combined cycle power plant in Bangladesh. This case consists of the HRSG (Heat Recovery Steam Generator) boiler foundation (Figure 4). The boiler is founded in a sandy, water-saturated soil, potentially liquefiable, by means of deep foundations.

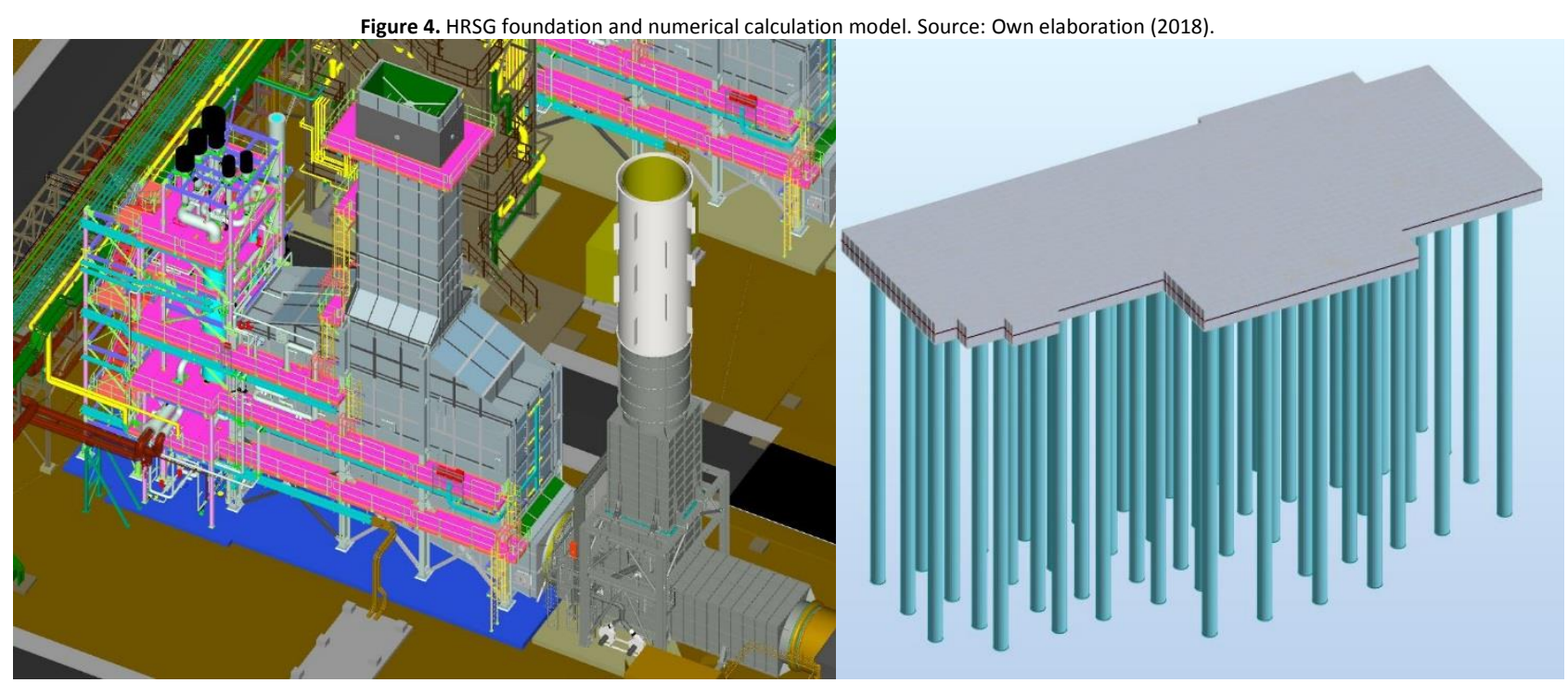

Background

As previously stated, the aim of this paper is to give an approach, in economic terms, of the unexpected costs related to geotechnical issues. Nevertheless, the risks that a project could face along all its life cycle are more numerous. The following paragraphs are focused on developing the main ones.

As the EPC is a contracting system, some authors focused their efforts in clarifying how to deal with the inherent risks of the contract and how to allocate them between owner and contractor (Galloway, 2009).

The "Silver book" (FIDIC, 2017) performs a risk analysis, from the geotechnical point of view, based on the analysis of the "Tender" documentation looking for the best way to raise a claim to the final client if the real geotechnical scenario differs from the Tender information. 
Bali \& Apte (2014) published a risk analysis for an EPC project based on a real construction case. The authors developed their research with 19 risks that are susceptible to appear in the project, nevertheless they didn't take into consideration the geotechnical risk.

More recently, in 2018, Thweatt and Long (Thweatt \& Long, 2017) published other risk analysis for construction projects in developing countries. They identified risks related with corruption, international fraud, meteorological events, and risks related with the local communities. Once again, the geotechnical risk was not taken into consideration.

Related with corruption risks (Locatelli, Mariani, Sainati, \& Greco, 2017) identified corruption as one of the major impediments to the development of emerging countries. They presented the different types of corruptions and the characteristics of projects that are more likely to suffer from it, and stated that corruption is particularly relevant for large and uncommon projects where the public sector acts as client/owner or even as the main contractor. The main conclusion was that corruption does not simply lead to extra cost and delay, but also increases the transaction costs such the effort to set a defined procurement and controlling system.

Guerin (2017) developed a risk assessment on the construction stage of a utility-scale solar energy (USSE) project. This project confirmed and clarified the nature of environmental and community risks to be expected on Australian construction sites. For example, the large number of approval conditions (set by the relevant regulatory authorities; state and local) for the construction stage of the project, were found arguably excessive compared with the risk profile of the project. The environmental and community risks of greatest concern (including a lack of common understanding of expectations for local job opportunities), were a major problem to be faced by the EPC contractor.

More related with the local communities (Di Maddaloni \& Davis, 2017) developed an extant research in order to identify connections and major assumptions on the influence of stakeholders in major Public Infrastructure and Construction projects (PIC), at the local community level. They found that research on stakeholder management has been focused strongly on those stakeholders able to control project resources, whilst the effect on the legitimate 'secondary stakeholders', such as the local community, remains widely unexplored. Due to the unavoidable impact of major PIC on both people and places, it is concluded that seeking local community opinions in the initiation phase of the project and monitoring the megaproject impact at the local level can help to improve project performance.

Finally, Callegari, Szklo, \& Schaeffer (2018) estimated the probability distribution functions of cost overruns and delays in the construction of power generation projects, with a particular focus on mega hydroelectric dams recently built in Brazil. Results show that construction costs were, on average, 97.53\% above the initial estimates. For the delays, the construction completion time had an average increase of $74.28 \%$, or 3.5 years. The essential statistical message they obtained was that megaprojects fail to deliver the economies of scale embedded in large projects because the exposure to risk is disproportionate to the financial economies they can generate.

On the other hand, from the point of view of the technical analysis of the detected pathologies, in cases 1 and 2 a forensic analysis was carried out in order to establish the causes of the pathology and to develop a suitable solution.

The case 1 publication (González_Nicieza, Ordiales_Martínez, Laín_Huerta, Laín_Huerta, \& Álvarez-Fernández, 2017) and the case 2 publication (Ordiales_Martínez, Álvarez-Fernández, \& González-Niieza, 2018) show the works and the studies that were needed to identify and solve the pathologies that appeared in the real construction projects.

\section{Methodology}

Each case needs a specific approach to determine the main causes of the failure and its consequences and, in this way, find a suitable solution and calculate the associated costs.

\section{Case 1 methodology}

Previously, a failure in the concrete pipeline was studied (González_Nicieza et al., 2017) the methodology proposed in this document was assumed in the development of the technical analysis of case 1.

In order to evaluate the damage, several in situ tests were carried out. Some sections of the pipe were dug up, so the surrounding soil could be characterized.

Simultaneously, some pipe rings were tested within situ load tests, in order to evaluate its real resistance (Figure 5). 

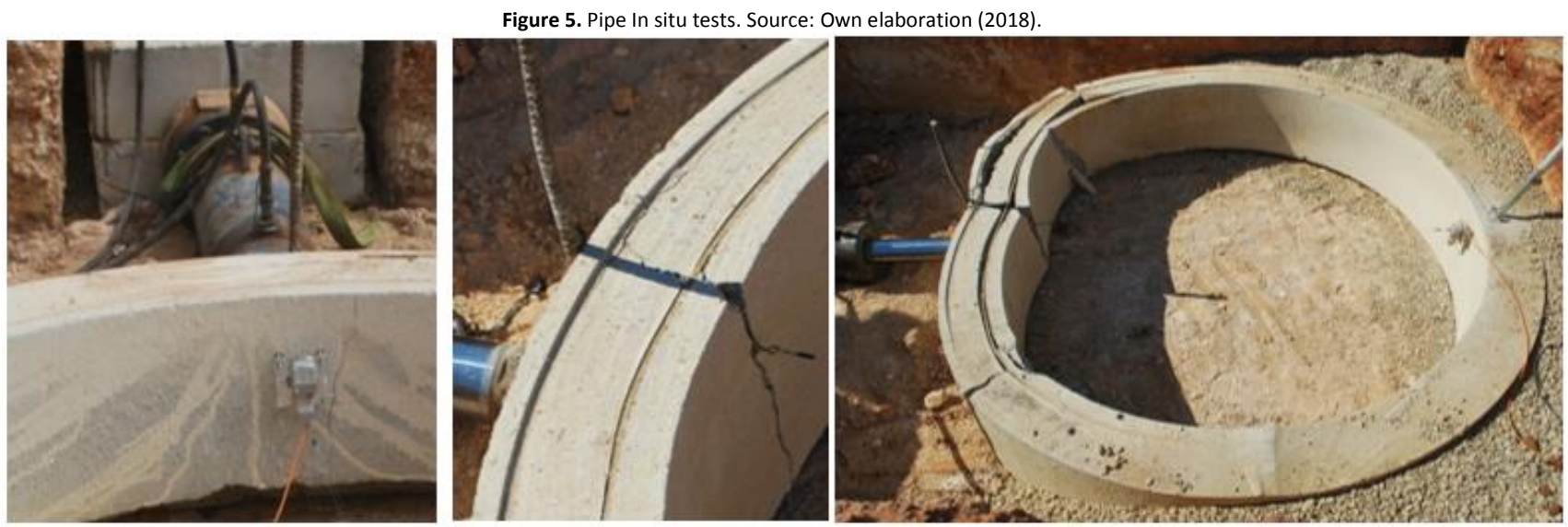

From the in situ tests, a series of numerical models were developed, in order to evaluate the long-term stability of the pipe and to develop a bench test to check different solutions.

The correlation between the in-situ tests and the numerical results let us establish as a solution the application of GIPL (Grouted In Place Linner) (Vuuren, 2012) methodology to the damaged section of the pipe. This solution increased the pipe wall thickness and in consequence, its maximum load resistance. The planned grout thickness, in this case, was 50 $\mathrm{mm}$. This solution involved a PVC profile adjusted to the pipe inner wall and filled with grout as can be observed in the following picture (Figure 6).

Figure 6. Grouted in Line methodology. Source:(Vuuren, 2012). Grouted lining systems for the renovation of old steel pipelines and the design of new pipelines.

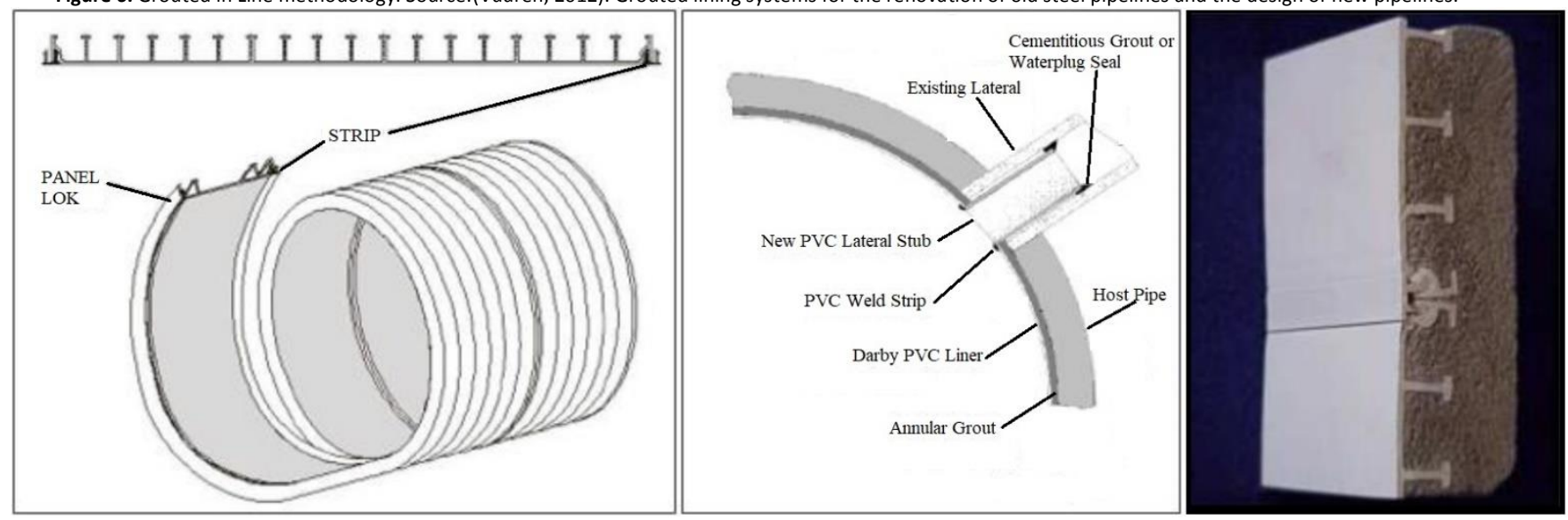

From a structural point of view, this system represents a structural rehabilitation system classified as TYPE I according to the established criteria in the "Sewerage Rehabilitation Manual" published periodically by the Water Research Council (WRC, 2001) over the last 25 years.

\section{Case 2 methodology}

Those pathologies and measurements explained in previous sections show that the developed settlements are far from the expected ones. Due to that, two hypotheses can be considered:

- Soil conditions, both at the support level and in deeper layers under the foundation, do not correspond to the conditions obtained in the geotechnical study carried out for the foundation calculation.

- The structural process has not been appropriate or it has affected the geotechnical properties of the soil.

In order to study the previously explained hypotheses, a data research and analysis campaign was developed, including both the geotechnical information and the constructive process.

Once all data was collected, several numerical models were developed in order to ensure the stability of the structure and to crosscheck the original calculation's inputs (Figure 7). 


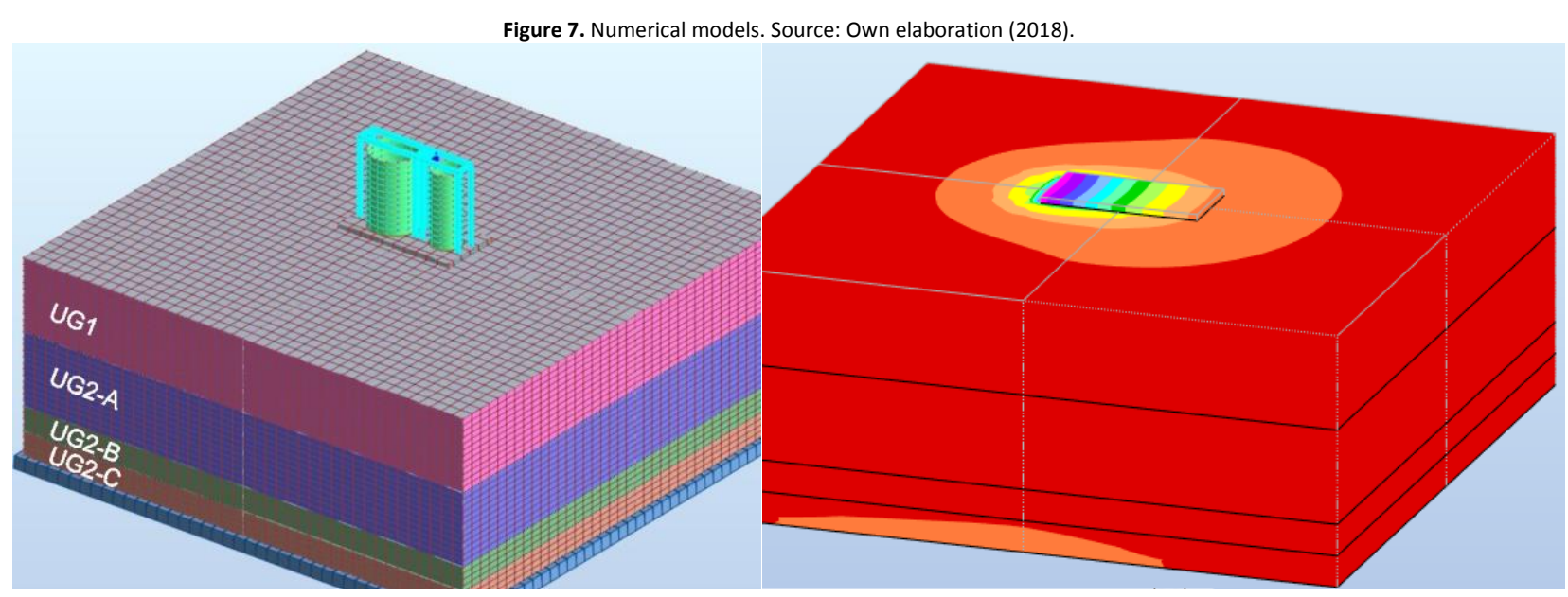

From the models, two possible solutions can be applied:

- Improving the current foundation slab by use of micro piles.

- Improving the soil bearing resistance by use of a soil improvement treatment. This can be done by means of repetitive and selective mortar injections.

After consulting several companies specializing in deep foundation execution, the use of micro piles was rejected due to the difficulty in ensuring the final top of the concrete level for the whole slab. Additionally, the thickness of the executed slab would not have enough bend resistance if it was micro piled in the perimeter. Furthermore, it was impossible to position the micro piling machinery in order to execute micro piles in the middle of the slab.

Henceforth, the executed treatment consisted of soil improvement by means of 27 mortar injections in several phases (Cuéllar, 2004).

\section{Case 3 methodology}

From a geotechnical point of view, the existence of liquefiable layers means a complete loss of the pile lateral support and a negligible contribution of this layer to the pile shaft resistance.

In this case, $600 \mathrm{~mm}$ diameter piles are used, due to the available machinery in the project area.

The total pile resistance (toe resistance plus shaft resistance) was analysed in both scenarios: $4 \mathrm{~m}$ liquefiable layer (Maruzen., 2003) vs. $10 \mathrm{~m}$ liquefiable layer (Seed \& Idris, 1970). Those analyses were carried out based on the technical report published in 2010 by the National Highway Institute FHWA-NHI-10-016 Drilled Shafts - Construction Procedures and LRFD Design Methods (Brown, Turner, \& Castelli, 2010), and the methodology explained by (Villavicencio A, Breul, Bacconnet, Fourie, \& Espinace A, 2016) during the liquefaction assessment, obtaining the following results (Table 1).

Table 1. Maximum bearing resistance. Source: Own elaboration (2018).

\begin{tabular}{lccccc}
\hline & $\begin{array}{c}\text { Diameter } \\
(\mathrm{m})\end{array}$ & $\begin{array}{c}\text { Length } \\
(\mathrm{m})\end{array}$ & $\begin{array}{c}\text { Shaft } \\
\text { Resistance } \\
(\mathrm{kN})\end{array}$ & $\begin{array}{c}\text { Toe } \\
\text { Resistance } \\
(\mathrm{kN})\end{array}$ & $\begin{array}{c}\text { Total } \\
\text { Resistance } \\
(\mathrm{kN})\end{array}$ \\
\hline No liquefaction & 0.60 & 19 & 961 & 260 & 1221 \\
4 m liquefaction & 0.60 & 19 & 938 & 260 & 1198 \\
10 m liquefaction & 0.60 & 19 & 788 & 260 & 1048 \\
\hline
\end{tabular}

As it can be observed, all the results cover the $1000 \mathrm{kN}$ load transferred from the foundation slab. In this way, the LRFD methodology proposed in the technical report published in 2010 by the National Highway Institute FHWA-NHI-10-016 Drilled Shafts - Construction Procedures and LRFD Design Methods (Brown et al., 2010), is fulfilled:

Where:

$$
Q_{\text {des }} \leq Q_{\text {all }}=\frac{Q_{u l t}}{F S}
$$

- $\quad Q_{\text {des }}=$ Design load applied to the foundation 
- $\quad Q_{\text {all }}=$ allowable load

- $\quad$ Qult = ultimate load capacity

- $\quad \mathrm{FS}=$ global safety factor $(\geq 1)$

In addition, the centreline of every single pile is more than 2.5 times the diameter away from each other, so, the pile group effect can be considered negligible.

For the structural analysis purpose, two three-dimensional models were developed, the first one for the $3 \mathrm{~m}$ liquefiable layer case and the second one for the $9 \mathrm{~m}$ liquefiable layer case.

The lateral soil stiffness was modelled by means of springs, which elastic constant is set identical to the calculated soil stiffness based at the considered depth. Once the pile head loads are applied, the sectional stresses can be obtained to perform the structural analysis.

The three-dimensional model and the subsequent analysis was developed with the software "Autodesk Robot Structural Analysis" (Autodesk, 2010).

With this result, the pile calculated in the $10 \mathrm{~m}$ liquefiable layer needs a very elevated reinforcement amount in order to compensate for the lack of lateral support. The obtained reinforcement exceeds the recommended ratios, and thus, the pile design should be modified.

In this case, the pile was modified by increasing its diameter up to $800 \mathrm{~mm}$. By increasing the diameter, the toe and the shaft resistance rises too, so the pile length can be reduced. Re-doing the previous calculations, the $800 \mathrm{~mm}$ pile diameter with $16 \mathrm{~m}$ length achieves a total resistance adequate to the pile load transferred from the foundation slab.

Thus, cost comparisons will be done between the following situations:

- Japanese code methodology - $4 \mathrm{~m}$ liquefiable layer: $600 \mathrm{~mm}$ pile diameter and $19 \mathrm{~m}$ pile length.

- $\quad$ Seed \& Idriss methodology- $10 \mathrm{~m}$ liquefiable layer: $800 \mathrm{~mm}$ pile diameter and $16 \mathrm{~m}$ pile length.

Results

Once the incidents were analysed the cause could be established, and therefore, a solution proposed. The following paragraphs show the interpretative results, in economic terms, of each study case.

\section{Case 1 cost analysis}

The main budget lines involved in the rehabilitation cost are:

- Engineering manpower: An engineering team designated to analyse the problem, design the field test campaign, check the results and develop a suitable rehabilitation solution.

- In situ tests: The cost of the machinery and operational staff to develop in situ testing.

- Purchasing manpower: A purchasing team designated to find the best companies to execute de rehabilitation solution, receive the quotations, select the optimal quotation, write and sign the contracts.

- $\quad$ Pipe GIPL rehabilitation: The cost of the rehabilitation based on the selected quote by the purchasing team.

- Commissioning manpower: The cost of the commissioning team who ensured the long-term quality of the rehabilitation and makes regular inspections in order to maintain the operation of the pipe.

The following Table 2 summarizes all the considered costs.

It is important to notice that, in relative terms, a $1 \%$ extra cost over the total budget does not seem to be very important but this is an erroneous analysis. In the overall profit estimation for the project, a good outcome is considered around a $10 \%$ benefit ( $22500000 €$ from a $225000000 €$ budget). In this case, an unexpected expense of only a $1 \%$ ( $2250000 €$ ) reduces the global benefit to a $9 \%(20250000 €)$, which means a $10 \%$ benefit reduction ( $20250000 €$ instead of 22500000 $€)$. 


\begin{tabular}{lccc}
\multicolumn{4}{c}{ Table 2. Case 1 Cost analysis. Source: Own elaboration (2018). } \\
& Quantity & $\begin{array}{c}\text { Unitary cost } \\
(€)\end{array}$ & $\begin{array}{c}\text { Total cost } \\
(€)\end{array}$ \\
\hline $\begin{array}{l}\text { Engineering phase } \\
\text { Engineering manpower (hours) }\end{array}$ & 1000 & 60 & 60000 \\
$\begin{array}{l}\text { In situ test (hours) } \\
\text { Purchasing phase }\end{array}$ & 240 & 110 & 26400 \\
$\begin{array}{l}\text { Purchasing manpower (hours) } \\
\text { Rehabilitation phase }\end{array}$ & 160 & 60 & 9600 \\
$\begin{array}{l}\text { Pipe GIPL rehabilitation (ml) } \\
\text { Commissioning phase }\end{array}$ & 883 & 2350 & 2075050 \\
Commissioning manpower (ml) & 160 & 85 & 13600 \\
& & & 2184650 \\
Total rehabilitation cost $(€)$ & & & 225000000 \\
Total power plant budget $(€)$ & & & 0.97 \\
Rehabilitation vs total budget $(\%)$ & & & \\
\hline
\end{tabular}

\section{Case 2 cost analysis}

The main budget lines involved in the rehabilitation cost are:

- Engineering manpower: An engineering team designated to analyse the problem, design the field test campaign, check the results and develop a suitable rehabilitation solution.

- In situ tests: The cost of the machinery and operational staff to develop in situ testing.

- Purchasing manpower: A purchasing team designated to find the best companies to execute the rehabilitation solution, receive the quotations, select the optimal one, write and sign the contracts.

- $\quad$ Specialized contractor: The cost of the rehabilitation based on the selected quote by the purchasing team.

- Commissioning manpower: The cost of the commissioning team who ensures the long-term quality of the rehabilitation and makes regular inspections in order to maintain the operation of the facility.

The following Table 3 summarizes all the considered costs.

\begin{tabular}{|c|c|c|c|}
\hline & Quantity & $\begin{array}{c}\text { Unitary cost } \\
(€)\end{array}$ & $\begin{array}{c}\text { Total cost } \\
(€)\end{array}$ \\
\hline \multicolumn{4}{|l|}{ Engineering phase } \\
\hline Engineering manpower (hours) & 600 & 60 & 36000 \\
\hline In situ test (hours) & 150 & 110 & 16500 \\
\hline \multicolumn{4}{|l|}{ Purchasing phase } \\
\hline Purchasing manpower (hours) & 160 & 60 & 9600 \\
\hline \multicolumn{4}{|l|}{ Rehabilitation phase } \\
\hline Specialized contractor (hours) & 700 & 550 & 385000 \\
\hline \multicolumn{4}{|l|}{ Commissioning phase } \\
\hline Commissioning manpower (ml) & 160 & 85 & 13600 \\
\hline Total rehabilitation cost $(€)$ & & & 460700 \\
\hline Total power plant budget $(€)$ & & & 225000000 \\
\hline $\begin{array}{l}\text { Rehabilitation vs total budget } \\
\text { (\%) }\end{array}$ & & & 0.20 \\
\hline
\end{tabular}


In this case, the effective cost of the rehabilitation versus the total power plant budget is not relevant, but this example is included in this paper as an example of an essential facility failure. In this case, the relevant cost is not economic, but time. The failure of this facility delays the power plant start up, so the final milestone cannot be fulfilled and due to that, time penalties are applied.

The most usual penalty fee in EPC contracts is $0.5 \%$ of the total budget per delayed week. So, it is easy to show that a delay of only two weeks in the start-up of the power plant represents a cost of $1 \%(2250000 €)$ plus the rehabilitation cost. This means a reduction of the gloss benefit of down to an $8.80 \%$ (19789300 € instead of $22500000 €$ ).

Table 4 shows the considered costs including the penalty fees due to two weeks delay in the plant start up.

\begin{tabular}{|c|c|c|c|}
\hline & Quantity & $\begin{array}{c}\text { Unitary cost } \\
(€)\end{array}$ & $\begin{array}{c}\text { Total cost } \\
(€)\end{array}$ \\
\hline \multicolumn{4}{|l|}{ Engineering phase } \\
\hline Engineering manpower (hours) & 600 & 60 & 36000 \\
\hline In situ test (hours) & 150 & 110 & 16500 \\
\hline \multicolumn{4}{|l|}{ Purchasing phase } \\
\hline Purchasing manpower (hours) & 160 & 60 & 9600 \\
\hline \multicolumn{4}{|l|}{ Rehabilitation phase } \\
\hline Specialized contractor (hours) & 700 & 550 & 385000 \\
\hline \multicolumn{4}{|l|}{ Commissioning phase } \\
\hline Commissioning manpower (ml) & 160 & 85 & 13600 \\
\hline Total rehabilitation cost $(€)$ & & & 460700 \\
\hline Total power plant budget $(€)$ & & & 225000000 \\
\hline Rehabilitation vs total budget (\%) & & & 0.20 \\
\hline Delay penalty fee $(€)$ & 2 weeks & 1125000 & 2250000 \\
\hline Total failure cost $(€)$ & & & 2710700 \\
\hline Total failure cost vs total budget (\%) & & & 1.20 \\
\hline
\end{tabular}

\section{Case 3 cost analysis}

For the purpose of cost analysis, the following budget lines were considered:

- Excavation and material transportation to landfill

- Thixotropic mud

- Concrete

- $\quad$ Reinforcement steel

The following Table 5 summarizes all the considered costs.

As it can be observed in Table 5, depending on the design code selection, the unitary pile cost can double.

For the complete construction of a $450 \mathrm{MW}$ combined cycle power plant, it is very common to execute around 2200 piles. Although it appears to be a very high number of piles, it must be taken into consideration that the construction of a solar thermal Power Plant of just $50 \mathrm{MW}$ needs more than 8000 piles just in the solar field.

Extrapolating the unitary pile cost to the total projected amount of piles. 
Table 5. Case 3 Cost analysis. Source: Own elaboration (2018).

\begin{tabular}{|c|c|c|c|}
\hline & $\begin{array}{c}\text { Pile } \\
\text { D } 600 \text { mm L } 19 \text { m }\end{array}$ & $\begin{array}{c}\text { Pile } \\
\text { D } 800 \text { mm L } 16 \text { m }\end{array}$ & $\begin{array}{c}\text { Difference } \\
\text { (\%) }\end{array}$ \\
\hline \multicolumn{4}{|l|}{ Excavation and transport } \\
\hline Unit measurement $\left(\mathrm{m}^{3}\right)$ & 5.37 & 8.04 & \\
\hline Unit cost $\left(€ / \mathrm{m}^{3}\right)$ & 5.00 & 5.00 & \\
\hline Total cost $(€)$ & 26.86 & 40.21 & 149.71 \\
\hline \multicolumn{4}{|l|}{ Thixotropic mud } \\
\hline Unit measurement $\left(\mathrm{m}^{3}\right)$ & 5.37 & 8.04 & \\
\hline Unit cost $\left(€ / \mathrm{m}^{3}\right)$ & 3.50 & 3.50 & \\
\hline Total cost $(€)$ & 18.80 & 28.15 & 149.71 \\
\hline \multicolumn{4}{|l|}{ C30 concrete } \\
\hline Unit measurement $\left(\mathrm{m}^{3}\right)$ & 5.37 & 8.04 & \\
\hline Unit cost $\left(€ / \mathrm{m}^{3}\right)$ & 90.00 & 90.00 & \\
\hline Total cost $(€)$ & 483.49 & 723.82 & 149.71 \\
\hline \multicolumn{4}{|c|}{ Reinforcement ASTM A615 } \\
\hline Unit measurement (kg) & 460.70 & 1273.50 & \\
\hline Unit cost $(€ / \mathrm{kg})$ & 0.85 & 0.85 & \\
\hline Total cost $(€)$ & 391.60 & 1082.48 & 276.43 \\
\hline Total unitary cost $(€)$ & 920.75 & 1874.66 & 203.60 \\
\hline
\end{tabular}

\begin{tabular}{|c|c|c|c|}
\hline & $\begin{array}{c}\text { Pile } \\
\text { D } 600 \text { mm L } 19 \text { m }\end{array}$ & $\begin{array}{c}\text { Pile } \\
\text { D } 800 \text { mm L } 16 \text { m }\end{array}$ & $\begin{array}{c}\text { Difference } \\
(\%)\end{array}$ \\
\hline Total unitary cost $(€)$ & 920.75 & 1874.66 & 203.60 \\
\hline Total pile cost (2.200 piles) & 2025648 & 4124250 & 203.60 \\
\hline
\end{tabular}

As it can be observed in table 6 , the cost difference due to the regulations rises up to $2100000 €$. In the overall profit estimation for the project, a good outcome is considered around $10 \%$ (30000000 $€$ from a $300000000 €$ budget). In this case, the cost difference between regulations $(2100000 €)$ reduces the gloss profit to $9.3 \%$ (27900000 $€$ instead of $30000000 €)$.

\section{Discussion}

To sum up, Table 7 shows a comparison of the impact of each study case in the estimated profit of the project.

\begin{tabular}{lccc}
\multicolumn{4}{c}{ Table 7. Cost impact comparative table. Source: Own elaboration (2019). } \\
& $\begin{array}{c}\text { Case 1 } \\
\text { total cost }(€)\end{array}$ & $\begin{array}{c}\text { Case 3 } \\
\text { total cost }(€)\end{array}$ & $\begin{array}{c}\text { Case 3 } \\
\text { total cost }(€)\end{array}$ \\
\hline Rehabilitation cost $(€)$ & 2184650 & 460700 & 0 \\
Delay penalty fee $(€)$ & 0 & 2250000 & 0 \\
Design overcost $(€)$ & 0 & 0 & 2098600 \\
Total failure cost $(€)$ & & & \\
Power plant budget $(€)$ & 2184650 & 2710700 & 2098600 \\
Failure cost vs total budget $(\%)$ & 225000000 & 225000000 & 300000000 \\
\hline
\end{tabular}

From the cost origin point of view, each case has been selected specifically to show three potential risks over the project's profit. As long as both case 1 and 2 implies a rehabilitation cost, it is important to analyse if the pathology can 
result in a delay penalty fee, when time becomes the most important parameter in order to minimize the cost. This difference can be observed in case 1 and case 2 columns in the previous chart, where two different impacts (rehabilitation cost in case 1 vs delay penalty fee in case 2 ) leads to a similar average reduction of the project profit.

Moreover, previously to the execution phase, case 3 shows how a wrong code selection at the beginning of the project could have the same cost impact in the project as an unforeseen geotechnical issue at site.

In average, the impact of an unforeseen problem or a dubious code selection could reach $10 \%$ of the estimated profit of the contract. Nevertheless, depending on the project's scale and the ambient factors, construction costs could also increase rapidly as happened to the recently built hydroelectric dams in Brazil where construction costs were, on average, $97.53 \%$ above the initial estimates.

The following chart shows the statistical summary of costs overruns (\%) for each generation technology. As it can be observed, all the technologies, which may be susceptible to be executed under an EPC contract, are liable to incur in cost overruns.

\begin{tabular}{|c|c|c|c|c|c|c|}
\hline & & Hydro & Nuclear & Thermo & Wind & Solar \\
\hline \multicolumn{2}{|c|}{ Number of projects } & 61 & 180 & 36 & 35 & 39 \\
\hline \multicolumn{2}{|c|}{ Number of projects with costs overrun } & 47 & 175 & 24 & 20 & 16 \\
\hline \multirow[t]{3}{*}{ Cost overrun (\%) } & Mean & 70.6 & 117.3 & 12.6 & 7.7 & 1.3 \\
\hline & Min & 0.9 & 1.3 & 1.2 & 0.4 & 2 \\
\hline & Max & 512.7 & 1279.7 & 120 & 44.4 & 50 \\
\hline
\end{tabular}

Focusing on the impact related to geotechnical risk, it has been concluded that a representative increase of the earlystage studies resources of the project is highly recommended because it has been demonstrated that those extra cost are recovered during the construction phase. In this regard, one of the main problems is that there is no usual practice, guide or computer tool that takes into account the specificity of the "soil risk" and its impact depending on the phase of the project or its typology.

Starting from a deep analysis of the geological-geotechnical information of the EPC projects executed within the company, the lessons learned, and through KDD (Knowledge Discovery in Databases) and DM (Data Mining) systems, the development of a Geological-Geological Risk Management System is proposed. This system will allow the different technicians involved in the project to obtain a precise and specific evaluation of the geotechnical risks, as well as, the different actions to be executed to mitigate or eliminate them.

The implementation of this system would generate the following benefits:

- Minimize deviations in time and cost of EPC projects: knowing, even in the tender phase, the geologicalgeotechnical risks that the project may face throughout the life cycle, and the possible contingency measures to implement, if necessary, at each stage of it.

- Apply preventive or corrective measures: early identification of geological-geotechnical risks in order to develop preventive measures and monitoring the residual risk after their application. This generally being more economical than after the fact.

Nowadays, the geological-geotechnical risks are not usually identified in advance, so once they occur, the actions are usually limited to solving the problem that arises (repetition of field campaigns, execution of a new filling, redesign of foundations, etc.) that usually involve high economic costs and/or delays.

Regarding the cost due to the execution of an unexpected rehabilitation:

- Unforeseen accidents and failures are susceptible to occurrences during the execution phase of the project. It is important to understand whether this failure will only involve the monetary cost of the rehabilitation or if it endangers time dependent penalty fees.

- If the failure only involves the monetary cost of the rehabilitation, the only thing that can be done is to try to optimize the work schedules (engineering, procurement, construction) in order to minimize the number of hours to be paid. 
Regarding the cost due to penalty fees:

- If the unforeseen failure could cause time dependent penalty fees, the most important action is to determine the balance point between the cost of the rehabilitation works and the time involved in those works. Usually, quicker works are more expensive, but this extra cost can be compensated for by avoiding the penalty fees payment.

- In general terms, time is the governing variable, and thus, reducing the rehabilitation work schedule is the best way to minimizing profit reduction.

Regarding the correct regulation selection at the beginning of the project:

- At the beginning of the project it is essential to conduct an extensive analysis of the obligatory regulations for the project. It is also important to identify those points, which are not specifically covered by the regulations, and remain subject to the design criteria.

- The use of sufficient engineering hours at the early stages of the project, in order to analyse different scenarios, involves a substantial initial cost in terms of manpower hours and resources. Nevertheless, if those resources are properly used, and this means taking the right decisions regarding the right use of the involved regulations, the initial costs are widely recovered during the construction phase.

As it has been stated, the unforeseen geotechnical issues have an important impact in the project profit. The average impact of an unforeseen geotechnical problem or a dubious code selection can reach $10 \%$ of the estimated profit of the contract.

The current state covers several approaches to the risk analysis in the EPC contracts development, but the unforeseen geotechnical issues are outside of those analysis. This lack of geotechnical related risk analysis development grounds this investigation.

In addition, currently no specific software able to identify and alert about geotechnical risks exists. A future investigation line could be to develop a computer tool based on KDD (Knowledge Data Discovery) and DM (Data Mining) that helps Project Managers to develop a geotechnical risk assessment at the early stages of the project, so the impact of the unforeseen incidents could be minimized.

\section{References}

Autodesk. (2010). Autodesk ${ }^{\circledR}$ Robot TM Structural Analysis Professional 2010 Training Manual - Metric Version. Database, (November 2009), 1-178.

Bali, R., \& Apte, P. M. . (2014). Risk Management in EPC Contract - Risk Identification. IOSR Journal of Mechanical and Civil Engineering, 11(1), 07-12. https://doi.org/10.9790/1684-11140712

Brown, D. A., Turner, J. P., \& Castelli, R. J. (2010). Drilled Shafts: Construction Procedures and LRFD Design Methods.

Callegari, C., Szklo, A., \& Schaeffer, R. (2018). Cost overruns and delays in energy megaprojects: How big is big enough? Energy Policy, 114(November 2017), 211-220. https://doi.org/10.1016/j.enpol.2017.11.059

Concrete Pipe Design Manual. (2011). American Concree Pipe Association. https://doi.org/10.1007/978-1-4757-0857-8_19

Cuéllar, V. (2004). Inyecciones por fracturación e inyecciones de impregnación. In CEDEX (Ed.), Jornadas Técnicas SEMSIG - AETESS. Nº4. Mejora del terreno mediante inyecciones y jet grouting (pp. 11-33). Madrid, Spain.

Di Maddaloni, F., \& Davis, K. (2017). The influence of local community stakeholders in megaprojects: Rethinking their inclusiveness to improve project performance. International Journal of Project Management, 35(8), 1537-1556. https://doi.org/10.1016/j.ijproman.2017.08.011

DLA Piper (2011). EPC Contracts in the Power Sector. Asia Pacific Projects Update. Retrieved from https://www.dlapiper.com/en/australia/insights/publications/2012/02/epc-contracts-in-the-power-sector/FIDIC. $\quad$ (2017). EPC/Turnkey Contract 2nd Ed (2017 Silver Book). Fédération Internationale des Ingénieurs-Conseils (FIDIC).

Galloway, P. (2009). Design-Build / EPC Contractor's Heightened Risk - Changes. Journal of Legal Affairs and Dispute Resolution in Engineering and Construction, 1(1), 7-15.

González_Nicieza, C., Ordiales_Martínez, V., Laín_Huerta, R., Laín_Huerta, C., \& Álvarez-Fernández, M. I. (2017). Failure analysis of a cracked concrete pipe in a $50 \mathrm{MW}$ thermosolar power plant. Engineering Failure Analysis, 79, 656-671.

Guerin, T. F. (2017). Evaluating expected and comparing with observed risks on a large-scale solar photovoltaic construction project: A case for reducing the regulatory burden. Renewable and Sustainable Energy Reviews, 74, 333-348.

Herrera, G., Fernández, J. A., Tomás, R., Cooksley, G., \& Mulas, J. (2009). Advanced interpretation of subsidence in Murcia (SE Spain) using A-DInSAR data - Modelling and validation. Natural Hazards and Earth System Science, 9(3), 647-661. https://doi.org/10.5194/nhess-9-647-2009 
Locatelli, G., Mariani, G., Sainati, T., \& Greco, M. (2017). Corruption in public projects and megaprojects: There is an elephant in the room! International Journal of Project Management, 35(3), 252-268. https://doi.org/10.1016/j.ijproman.2016.09.010

Masahiro Shirato, Fukui, J., Unjoh, S., Hoshikuma, J. (2003). Specifications for highway bridges, V Seismic Design. In Limit State Design in Geotechnical Engineering Practice - The International Workshop LSD 2003, Massachusetts, USA, December, 2003.

Ordiales_Martínez, V., Álvarez-Fernández, M., \& González-Niieza, C. (2018). Failure analysis of subsidence in an effluent treatment plant in a thermosolar power plant. Engineering Failure Analysis, 91, 419-432.

Seed, H. B., \& Idris, I. M. (1970). Asimplified Procedure for Evaluating Soil Liquefaction Potential. Berkeley, California.

Thweatt, W. T., \& Long, R. J. (2017). EPC Contract Risk Analysis Associated with Onshore Projects in Developing Countries. Long International, (303), $1-31$.

Villavicencio A, G., Breul, P., Bacconnet, C., Fourie, A., \& Espinace A, R. (2016). Liquefaction potential of sand tailings dams evaluated using a probabilistic interpretation of estimated in-situ relative density. Revista de La Construcción, 15(2), 9-18. https://doi.org/10.4067/s0718$915 \times 2016000200001$

Vuuren, S. van. (2012). Water Research Commission reports: Grouted lining systems for the renovation of old steel pipelines and the design of new pipelines (Report no 1448/1/12). Retrieved from http://www.wrc.org.za/mdocs-posts/1448-1-12/

WRC. (2001). Sewerage rehabilitation manual. 4th edition. Volume I - rehabilitation planning. 